\title{
Anaerobic Hydrolytic Degradation of Cefpodoxime Proxetil in the Presence of UV Irradiation and in Darkness: Kinetics and pH Effect
}

\author{
Ender Biçer, ${ }^{*}$ Neslihan Özdemir, and Serkan Özdemir \\ Department of Chemistry, Faculty of Arts and Sciences, Ondokuz Mayls University, 55139 Atakum-Samsun, Turkey
}

RECEIVED MARCH 14, 2012; REVISED DECEMBER 6, 2012; ACCEPTED JANUARY 4, 2013

\begin{abstract}
In this study, the anaerobic hydrolytic degradation of cefpodoxime proxetil (CP) in the presence of UV-light irradiation and in darkness has been studied at Britton-Robinson (B-R) buffer solutions ( $\mathrm{pH}$ $2.5-11$ ) by cyclic and square-wave voltammetry techniques. By means of these electrochemical techniques, the hydrolytic degradation of $\mathrm{CP}$ was successfully followed. The $\mathrm{pH}$ effect on this degradation was also investigated. In darkness, the decrease in the peak current of $\mathrm{CP}$ was not practically observed at the acidic and physiological pHs (2.5, 5.0 and 7.4). But, in the basic medium (pH 9.0 and 11.0), a decrease in the peak current was detected. On the other hand, UV irradiation caused a decrease in the peak current of $\mathrm{CP}$ and a positive shift in its cathodic peak potential. Under the UV irradiation, the maximum stability of $\mathrm{CP}$ was observed in $\mathrm{B}-\mathrm{R}$ buffer of $\mathrm{pH} 5$. It has been determined that $\mathrm{UV}$ irradiation has a great effect on hydrolytic degradation of $\mathrm{CP}$ at basic medium. On the other hand, at $\mathrm{pHs} \geq 7.4$, a new peak has been also obtained at more positive potential than that of the first reduction peak of $\mathrm{CP}$. The current of this peak increases by increasing UV irradiation time. This peak could be assigned to the reduction of a new electroactive product which was formed from the hydrolytic degradation of $\mathrm{CP}$ under UV irradiation. The hydrolytic degradation reaction of CP followed pseudo-first order kinetics.(doi: 10.5562/cca2071)
\end{abstract}

Keywords: cefpodoxime proxetil, hydrolytic degradation, $\mathrm{pH}$ effect, voltammetry, UV-irradiation, darkness

\section{INTRODUCTION}

The stability of drugs towards heat, moisture, oxidation and exposure to light is a topic of great practical interest owing to considerable complexity. ${ }^{1,2}$ Since degradation products of pharmaceutical compounds can cause undesirable side effects in patients, ${ }^{3}$ the information on the photodegradation of drugs is urgently needed for the safety of human beings. Also, the degradation of a pharmaceutical leads to increasing amounts of degradation products, therefore, the investigation of stability characteristics and degradation profile of a pharmaceutical is important. ${ }^{3}$

Cephalosporins are the second major group of $\beta$ lactam antibiotics. ${ }^{4} \mathrm{CP}$ (Scheme 1) is an orally absorbed broad spectrum third generation cephalosporin ester. This prodrug ester is deesterified in vivo into its active metabolite cefpodoxime. ${ }^{5}$

Stereo and structural isomers of CP (e.g. anti-CP and $\Delta^{2}$-CP, see Scheme 1) can be present as possible as degradation products ${ }^{6}$. Isomerization from $\Delta^{3}$-cephalosporin ester to its $\Delta^{2}$-isomer can be catalyzed by general and specific bases. ${ }^{6}$ Anti-cephalosporin ester yields from its syn-isomer as a function of photoisomerization under irradiation at $254 \mathrm{~nm}^{7}$
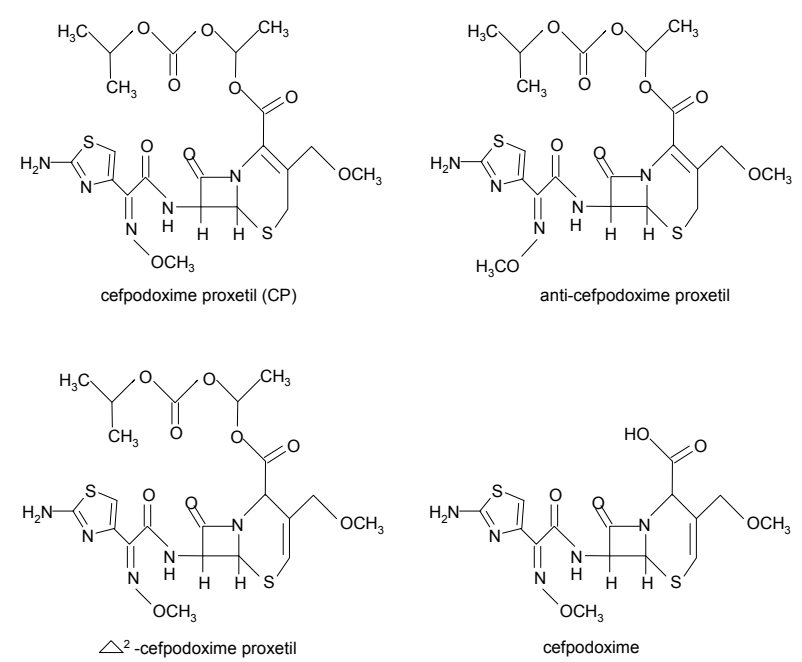

Scheme 1. Structures of CP and its some related substances.

The stabilities of $\mathrm{CP}$ in $20 \mathrm{mmol} \mathrm{dm}{ }^{-3} \mathrm{~K}_{2} \mathrm{HPO}_{4}$ methanol $(55: 45, v / v), 20 \mathrm{mmol} \mathrm{dm}{ }^{-3}$ ammonium acetate-methanol $(55: 45, v / v)$, L-histidine solution $(\mathrm{pH}$ 2.5)-methanol $(55: 45, v / v)$ as well as water-methanol $(55: 45, v / v)$ were investigated by Wang et al. ${ }^{6}$ at room

\footnotetext{
* Author to whom correspondence should be addressed. (E-mail: ebicer@omu.edu.tr)
} 
temperature for about $22 \mathrm{~h}$ via HPLC analysis. They reported $^{6}$ that approximately $75 \%$ of CP degraded in the phosphate solution, and about $4-6 \%$ of $\mathrm{CP}$ in acetate and L-histidine solution, but no obvious degradation occurred in water-methanol $(55: 45, v / v)$ at room temperature after about $22 \mathrm{~h}$.

$\mathrm{CP}$ has an asymmetric carbon at position 4 (Scheme 1) and is supplied racemic mixture of R- and S-enantiomers. ${ }^{8} \mathrm{CP}$ and other $\beta$-lactam antibiotic structures are known to degrade by hydrolysis in alkaline and acid solutions. ${ }^{8,9}$ In the alkaline media, CP undergoes ester hydrolysis and is converted into cefpodoxime (see Scheme 1) to exhibit its antibiotic activity. ${ }^{8,10-12}$ The degradation of $\mathrm{CP}$ in $0.01 \mathrm{~mol} \mathrm{dm}^{-3} \mathrm{HCl}, 0.01 \mathrm{~mol} \mathrm{dm}^{-3}$ $\mathrm{NaOH}, 0.1 \% \mathrm{H}_{2} \mathrm{O}_{2}$ and $1.0 \%$ hydroxylamine solutions was studied by Fukutsu et al. ${ }^{12}$ and its degradation products were characterized by HPLC and MS analysis. They reported $\mathrm{d}^{12}$ that $\mathrm{CP}$ was relatively stable in both the $0.01 \mathrm{~mol} \mathrm{dm}^{-3} \mathrm{HCl}$ and $0.1 \% \mathrm{H}_{2} \mathrm{O}_{2}$ solutions. However, CP was completely degraded in $0.01 \mathrm{~mol} \mathrm{dm}^{-3} \mathrm{NaOH}^{12}$ For the $1.0 \%$ hydroxylamine solution, $\mathrm{CP}$ was degraded rapidly. ${ }^{12}$

Hydrolysis of $\mathrm{CP}$ can proceed by a reversible base-catalyzed isomerization yielding the $\Delta^{2}$ cephalosporin ester which is rapidly cleaved to give the biologically in active $\Delta^{2}$-cephalosporin. ${ }^{8}$ The degradation of CP in $0.6 \mathrm{~mol} \mathrm{dm}^{-3}$ phosphate buffer (pH 7.4) at $37{ }^{\circ} \mathrm{C}$ over $24 \mathrm{~h}$ was studied using HPLC and NMR techniques by Stoeckel et al..$^{13}$ They reported ${ }^{13}$ that in phosphate buffer, the major degradation product was the $\Delta^{2}$-cephalosporin. The half-lives $\left(\mathrm{t}_{1 / 2}\right)$ for the diastereoisomers of $\mathrm{CP}$ were 2.5 and $2.2 \mathrm{~h}$, respectively. ${ }^{13}$

The stability of $\mathrm{CP}$ was also investigated in buffers of $\mathrm{pH}$ values $1.2,4.5,5.4$ and 6.8 for $24 \mathrm{~h}$ at $37^{\circ} \mathrm{C}$ by Kakumanu et al. ${ }^{14}$ According to this study, a strong influence of $\mathrm{pH}$ on the stability of $\mathrm{CP}$ was observed. The higher the $\mathrm{pH}$ of the buffer, lesser is the stability of $\mathrm{CP}$, and buffer with $\mathrm{pH} 1.2$ offered highest protection. There was a sudden increase in degradation of $\mathrm{CP}$ at $\mathrm{pH}$ 6.8. CP was stable for up to $12 \mathrm{~h}$ in all buffers except $\mathrm{pH}$ 6.8. Although the stability at $\mathrm{pH} 5.4$ was less compared to those of $\mathrm{pH} 1.2$ and 4.5, but the percentage of drug was maintained at $80 \%$ till $24 \mathrm{~h}$. At pH 6.8, about $55 \%$ of its content was degraded within $8 \mathrm{~h}$ and complete degradation occurred in $24 \mathrm{~h}$. The major degradation product was found to be cefpodoxime as analyzed by HPLC. ${ }^{14}$

The stability of $\mathrm{CP}$ in B-R buffers, at $\mathrm{pH} 2.0,4.0$, 6.0, 7.0, 8.0 and 10.0, was also studied at a temperature of $40{ }^{\circ} \mathrm{C}$ and its degradation products were determined by HPLC hyphenated techniques of LC-MS, LC-NMR and solvent-elimination LC-IR. ${ }^{3} \mathrm{CP}$ was not degraded under acidic to slightly acidic conditions, and no significant change of $\mathrm{CP}$ content was observed at $\mathrm{pH} 2.0$ or
4.0. Under neutral to alkaline conditions, $\mathrm{CP}$ was slightly degraded at $\mathrm{pH} 6.0$ but was degraded at $\mathrm{pH} 7.0$ and 8.0. At $\mathrm{pH} 10.0$, no detectable CP was observed after 2 h. ${ }^{3}$

The voltammetric behavior of $\mathrm{CP}$ was previously examined in $\mathrm{pH}$ range $2.0-12.0$ by using DPV and CV techniques. ${ }^{15}$ It was reported that $\mathrm{CP}$ gave two reduction peaks in the entire buffer system and these peaks were attributed to the reduction of azomethine group by twoelectron process in two steps. ${ }^{15}$ By means of cyclic voltammetry (CV) technique, no anodic peak was observed in the $\mathrm{pH}$ range for $\mathrm{CP} .{ }^{15}$ In addition, the peak potential of $\mathrm{CP}$ shifted towards a more negative potential along with an increase in the $\mathrm{pH}$ range. ${ }^{15}$ The optimum $\mathrm{pH}$ for $\mathrm{CP}$ was selected as $\mathrm{pH} 2.0$ where the first peak was sharp and reproducible and was preferred for the analysis. ${ }^{15}$

Electrochemical behavior of $\mathrm{CP}$ at dropping mercury electrode in the presence of some surfactants was also studied by Jain et al. ${ }^{16}$ Reduction potential of CP shifted negatively and peak current was increased significantly in the presence of cetyltrimethylammonium bromide (CTAB). In addition, two well defined, cathodic and diffusion controlled waves were observed for $\mathrm{CP}$ in the presence of CTAB in entire $\mathrm{pH}$ range. ${ }^{16}$ For the reduction of $\mathrm{CP}$, the postulated mechanism by Jain et $a l .{ }^{16}$ was agreed with that by Reddy et al ${ }^{15}$ For the voltammetric determination of CP in CTAB $\left(2.8 \times 10^{-4}\right.$ mol dm$\left.{ }^{-3}-0.14 \times 10^{-6} \mathrm{~mol} \mathrm{dm}^{-3}\right)$ and water $\left(2.8 \times 10^{-4}\right.$ mol $\left.\mathrm{dm}^{-3}-0.71 \times 10^{-6} \mathrm{~mol} \mathrm{dm}{ }^{-3}\right)$, the first reduction peak (wave I) was used by Jain et al. ${ }^{16}$

In fact, $\mathrm{CP}$ molecule has two electroactive sites (methoxyimino group and unsaturated $\mathrm{C}=\mathrm{C}$ bond, see Scheme 1). ${ }^{17,18}$ Zuman et al. reported the electroanalytical chemistry of cephalosporins and cefamycins. ${ }^{18}$ The reduction of the unsaturated $\mathrm{C}=\mathrm{C}$ bond occurs in two-electron process at potentials only slightly more positive than the reduction of $\mathrm{H}^{+}$ions from the supporting electrolyte used. ${ }^{18}$

The reduction of $\mathrm{CP}$ on the static mercury electrode in the $\mathrm{pH}$ range of $1.8-13.0$ was also studied by Aleksic et al. ${ }^{19}$ They reported ${ }^{19}$ that the $\mathrm{C}=\mathrm{N}-\mathrm{OCH}_{3}$ group was reducible in the whole $\mathrm{pH}$ range investigated $(1.8-13.0)$. In acidic and neutral medium, $\mathrm{pH}<7$, one well developed and sharp voltammetric peak (I) was present. In the $\mathrm{pH}$ range from 7 to 10.5 , this peak splitted, and two peaks, II and III, were present. ${ }^{19}$ The dependence of the DPV peak I current versus $\mathrm{pH}$ showed maximum at $\mathrm{pH}=3.5$, and both peak currents II and III reached the maximum at $\mathrm{pH} 9.0 .{ }^{19}$ Besides these three peaks, two more peaks (IV and V) were present. ${ }^{19}$ The former one was due to the reduction of methoxymino group at $\mathrm{pH}>10$, and the second one (at $\mathrm{pH}$ range of $1.8-6.5$ ) was attributed to the two electron reduction of unsaturated $\mathrm{C}=\mathrm{C}$ bond. ${ }^{19}$ 
Stabilities of CP and some cephalosporin antibiotics in solid state, drug formulation and solution were examined, ${ }^{3,6-14,20-24}$ however, no specific findings on the electrochemical detection of the anaerobic hydrolytic degradation of $\mathrm{CP}$ and its degradation kinetics under UV-irradiation were reported. Therefore, for the first time, the kinetics on anaerobic hydrolytic degradation process of CP solutions, exposed to UV light or at darkness in vitro was examined by some voltammetric techniques.

\section{EXPERIMENTAL}

\section{Reagents}

CP was obtained from Fargem A.Ş. (Düzce/Turkey) and used as received. All other reagents used were of analytical reagent grade. For all voltammetric experiments, $0.04 \mathrm{~mol} \mathrm{dm}^{-3} \mathrm{~B}-\mathrm{R}$ buffer solutions were used as the supporting electrolyte. High-purity nitrogen gas was used for deaeration. The $1.0 \times 10^{-3} \mathrm{~mol} \mathrm{dm}^{-3}$ stock solution of $\mathrm{CP}$ was daily prepared by dissolving its appropriate amount in a mixture of water (triply distilled and deionized) and ethanol (40:60, \% v/v).

\section{Apparatus}

The voltammetric measurements were carried out by using an EG\&G PAR Model 384B polarographic analyzer connected to an EG\&G PARC Model 303A SMDE polarographic cell (Princeton, NJ, USA) with three electrodes consisting of hanging mercury drop electrode (HMDE) as working electrode, an $\mathrm{Ag}|\mathrm{AgCl}| \mathrm{KCl}_{\text {sat. }}$ reference electrode and a platinum counter electrode. Voltamograms were monitored by means of ECDSOFT ${ }^{25}$ and Microsoft Excel package programs in a personal computer connected to the polarographic analyzer. The $\mathrm{pH}$ values of the buffer solution were measured with a Jenway $3010 \mathrm{pH}$ meter.

For the electrochemical analysis, the CP sample $(10 \mathrm{~mL})$ is contained in a borosilicate glass. The borosilicate glass transmits UV light $>310 \mathrm{~nm} .{ }^{26}$ Osram ultravitalux sun lamp (E27/ES) of 300 Watt was used as ultra-violet (UV) light source for UV-irradiation studies. Technical data for this light source: UVA $(315-400 \mathrm{~nm})$ radiated power is $13.6 \mathrm{~W}$ and UVB $(280-315 \mathrm{~nm})$ radiated power is $3.0 \mathrm{~W}^{27}$

\section{Procedure}

At the voltammetric method, ten milliliters solution containing $0.04 \mathrm{~mol} \mathrm{dm}^{-3} \mathrm{~B}-\mathrm{R}$ buffer with different $\mathrm{pHs}$ was transferred into an electrochemical cell. And then, the solution was deoxygenated, by bubbling with highly purified nitrogen gas. The voltamogram of the supporting electrolyte was recorded from 0.00 to $-2.00 \mathrm{~V}$. After the background voltamogram was obtained, an aliquot amount of solution of CP was added into the cell while maintaining the nitrogen atmosphere. Thus, the voltamograms of $2.91 \times 10^{-5} \mathrm{~mol} \mathrm{dm}{ }^{-3} \mathrm{CP}$ were recorded if not stated otherwise. And then, the CP solution in B-R buffer ( $\mathrm{pH} 2.50-11.00)$ was irradiated with UV-light at a distance of $30 \mathrm{~cm}$ for different times. The voltamograms of the $\mathrm{CP}$ solutions, irradiated were also recorded at different $\mathrm{pH}$ values. In addition, hydrolysis experiments were conducted in the CP solutions, kept in the dark. To evaluate the influence of $\mathrm{pH}$ on the hydrolysis of CP in the darkness, voltamograms were taken at different values of $\mathrm{pH}(2.5,5.0,7.4,9.0$ and 11.0) for different waiting times. The conditions of square-wave voltammetric measurements were usually as follows; a scan increment of $2 \mathrm{mV}$, a pulse height of $20 \mathrm{mV}$, a medium mercury drop size (surface area of $0.0154 \mathrm{~cm}^{2}$ ), equilibrium time of $5 \mathrm{~s}$, frequency of $100 \mathrm{~Hz}$ and a scan rate of $200 \mathrm{mV} \mathrm{s}^{-1}$. The cyclic voltammetric measurement was performed using a HMDE, an equilibrium time of $5 \mathrm{~s}$, and a scan rate of $500 \mathrm{mV} \mathrm{s}^{-1}$ unless stated otherwise.

All experiments were carried out at the ambient temperature of the laboratory $\left(\approx 25^{\circ} \mathrm{C}\right)$.

\section{RESULTS AND DISCUSSION}

\section{The Voltammetric Behavior of CP}

The voltammetric behavior of $\mathrm{CP}$ was studied in B-R buffer solutions (in the $\mathrm{pH}$ range of 2.5-11). In Figure 1 , typical square-wave voltamograms (SWVs) of CP at different $\mathrm{pH}$ values are shown. CP exhibits two welldefined peaks at very negative potentials in the entire buffer system. As can be also seen in Figure 1, these peaks are shifted towards more negative potentials as the $\mathrm{pH}$ increased.

Owing to no anodic peaks observed for CP (Figure $2 \mathrm{~A}$ ), the nature of the electrode process of these peaks was determined to be irreversible. The first one can be attributed to the reduction of $>\mathrm{C}=\mathrm{N}-\mathrm{OCH}_{3}$ group, but the second one at more negative potential $\left(E_{\mathrm{p}}=-1.3 \mathrm{~V}, \mathrm{pH} 5\right)$ is more likely due to the two electron reduction of unsaturated $\mathrm{C}=\mathrm{C}$ bond. ${ }^{15-19}$ The second reduction process is well known to take place at high negative potentials. ${ }^{18}$ At $\mathrm{pH} 11$, the additional peaks were observed at more positive potentials from that of the first reduction peak of $\mathrm{CP}$ (Figure 2C). One of the additional peaks was obtained at $-0.780 \mathrm{~V}$. At $\mathrm{pH}$ 11 , the amino group of $\mathrm{CP}$ is probably unprotonated. For CP, the dissociation equilibrium (due to the amino group of the thiazole ring) with a dissociation constant of $3.20 \pm 0.13$ was obtained from UV spectra in buffer solutions with the various $\mathrm{pH}$ values. ${ }^{28}$ Therefore, it can be said that $\mathrm{Hg}(\mathrm{I}) \mathrm{NH}-\mathrm{R}$ formed according to the sugges- 

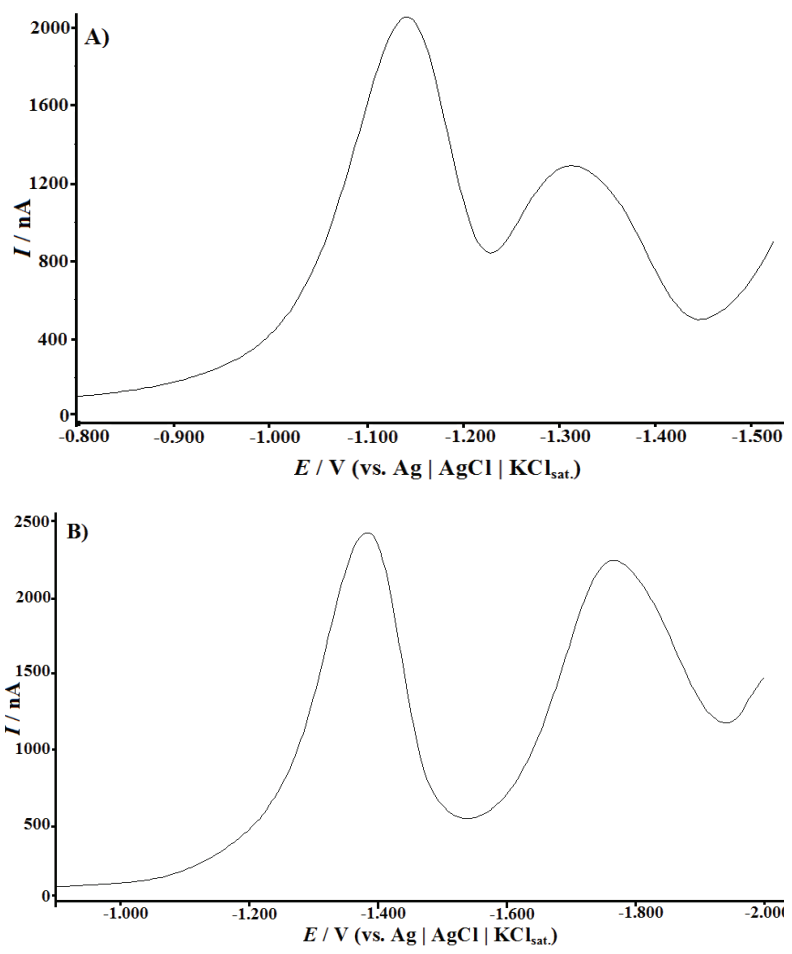

Figure 1. SWVs of $\mathrm{CP}$ at daylight in B-R buffer solutions. (A) $\mathrm{pH}=5$, (B) $\mathrm{pH}=9$ and $[\mathrm{CP}]=9.90 \times 10^{-6} \mathrm{~mol} \mathrm{dm}^{-3}$.

tion of other authors in the literature. ${ }^{15,29,30}$ Finally, this peak can be interpreted as a reduction of mercury salt of $\mathrm{CP}$ on the mercury surface under these conditions. Similarly, cefaclor exhibited a peak at $-0.67 \mathrm{~V}$ in B-R buffer $\mathrm{pH} 10 .^{31}$

Other additional peak which corresponds to the reduction of the alkaline degradation product of $\mathrm{CP}$ can be seen at $-0.904 \mathrm{~V}$ (Figure $2 \mathrm{C}$, a). A similar peak was obtained by the alkaline hydrolysis of cefaclor. ${ }^{32}$

\section{The Voltammetric Monitoring of Hydrolytic Degra- dation of CP under UV Irradiation}

To follow the kinetics of hydrolytic degradation of $\mathrm{CP}$ under UV radiation, its first peak was selected. CVs of CP after UV irradiation are also presented in Figure 2. As can be seen in Figures 2 and 3, with increasing irradiation time, the cathodic peak currents of $\mathrm{CP}$ significantly decreased and their potentials shifted to more positive potentials. The similar electrochemical results were also observed for the photolysis of some drugs under UV-irradiation. ${ }^{33-36}$ And also, a new peak, dependent on $\mathrm{pH}$ (Figure 2B, Inset), appears at different potential from those of reduction peaks of $\mathrm{CP}$. The formation of a new peak indicates the electroactivity of the degradation product of $\mathrm{CP}$. At $\mathrm{pH} 7.4$, a small reduction peak could be detected at $-0.746 \mathrm{~V}$ which may be attributed to the formation of a new electroactive degrada-
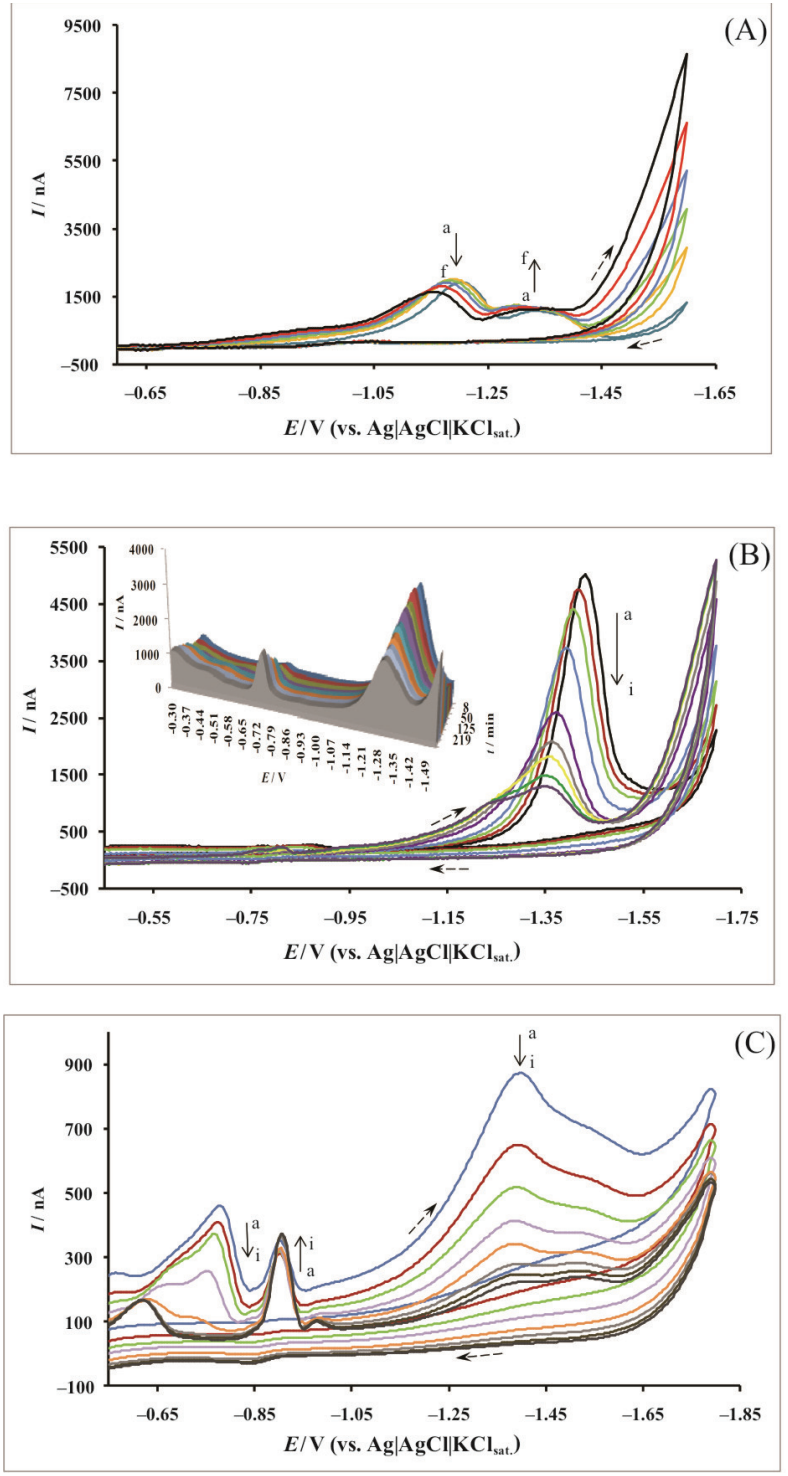

Figure 2. CVs of $\mathrm{CP}$ solutions, exposed to UV irradiation at different pHs. (A) pH 5; (a) 0, (b) 23, (c) 40, (d) 60, (e) 85, (f) 115 min. (B) pH 7.4; (a) 0, (b) 8, (c) 15, (d) 30, (e) 60, (f) 80, (g) 100, (h) 120, (i) 130 min. (C) $\mathrm{pH} \mathrm{11;} \mathrm{(a)} 0$ (day light), (b) 5, (c) 12, (d) 20, (e) 30, (f) 32, (g) 37, (h) 42, (i) $47 \mathrm{~min}$. The inset at Figure 2B shows $3 \mathrm{D}$ square-wave voltamograms of CP solution at different UV-irradiation times (t); (a) 8, (b) 24, (c) 50, (d) 67, (e) 125, (f) 163, (g) 219, (h) $279 \mathrm{~min}$.

tion product of $\mathrm{CP}$ on mercury electrode. On $\mathrm{CV}$ at $\mathrm{pH}$ 7.4 , this small peak is well defined by square-wave voltammetry (Figure 2B, inset). As can be seen in Figure $2 \mathrm{~B}$, the current of the peak at $-0.746 \mathrm{~V}$ increased by increasing UV-irradiation time. In a basic medium (i.e. $\mathrm{pH} 11$ ), this new peak was also observed at more negative potential $(-0.904 \mathrm{~V})$ in the absence of UVirradiation (Figure 2C, a). Probably, day light is sufficient for the formation of this peak at alkaline medium. At this basic medium, the current of this peak also 

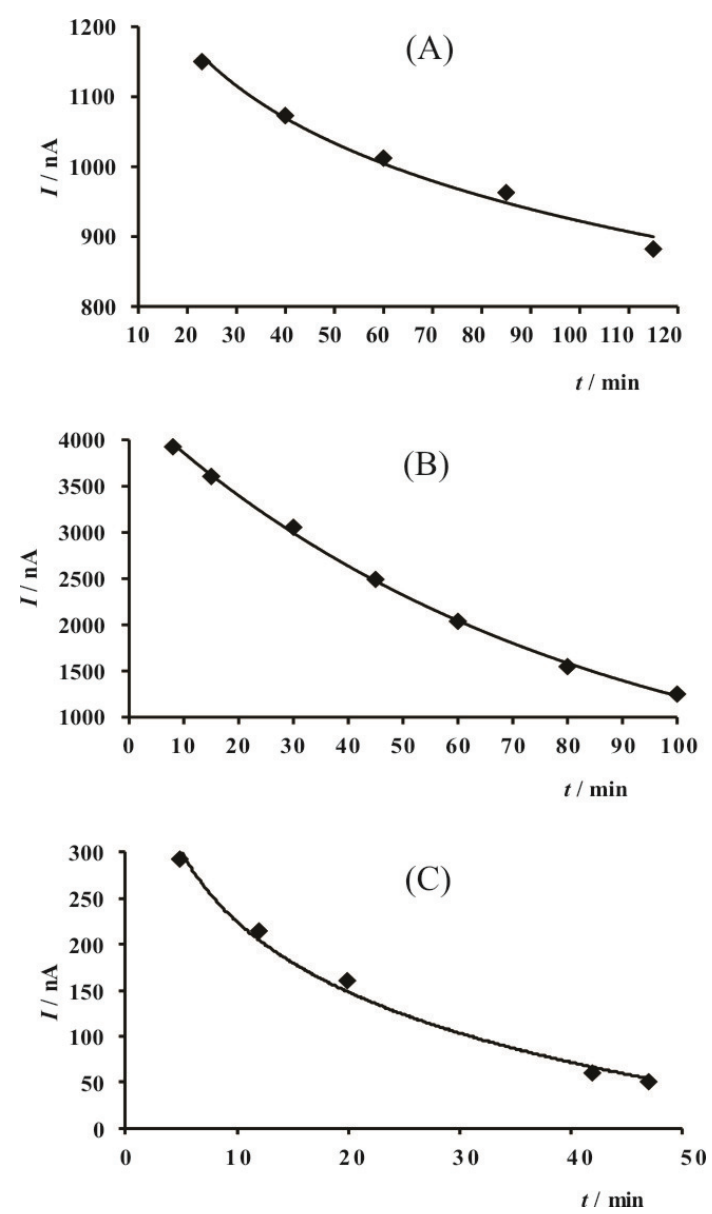

Figure 3. The effect of irradiation time on $\mathrm{CV}$ response of $\mathrm{CP}$ solution at different pHs: (A) 5, (B) 7.4 and (C) 11.

increased by increasing UV irradiation time (Figure 2C, b-i).

On the other hand, the peak (at $-0.780 \mathrm{~V}$ ), attributed to the reduction of mercury salt of $\mathrm{CP}$ on the mercury electrode surface at $\mathrm{pH} 11$ decreased and its potential shifted to more positive potentials by increasing UV-irradiation time (Figure 2C).

\section{The Voltammetric Monitoring of Hydrolytic Degra- dation of CP in Darkness}

To understand the effect of UV irradiation on the hydrolytic degradation of $\mathrm{CP}$, the voltamograms of $\mathrm{CP}$ solution in darkness have been also recorded with time for different $\mathrm{pH}$ values. At acidic pHs (2.5 and 5.0) and physiological $\mathrm{pH}$ (7.4), the peak currents of $\mathrm{CP}$ have not nearly changed (Figure 4). As regards to the obtained results, it can be concluded that $\mathrm{CP}$ is more stable under these circumstances. However, in the basic medium (pHs 9 and 11), the peak currents of CP decrease in a similar manner to the presence of UV irradiation (Figures 5 and 6). Moreover, according to the literature, ${ }^{8,12}$, $\mathrm{CP}$ is degraded to cefpodoxime, leaving $>\mathrm{C}=\mathrm{N}-\mathrm{OCH}_{3}$

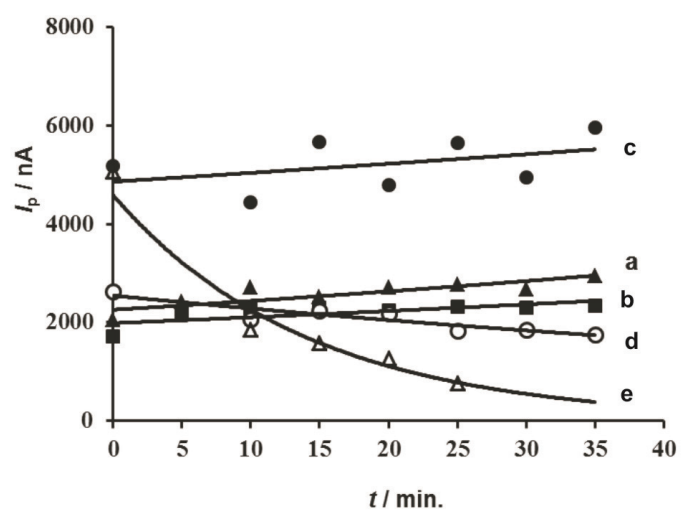

Figure 4. Kinetics of CP solution following a 35-min exposure to darkness at room temperature in B-R buffers with different pHs: a) $2.50(\boldsymbol{\Delta})$, b) $5.00(\mathbf{\bullet})$, c) $7.40(\bullet)$, d) $9.00(\circ)$, e) $11.00(\Delta)$.

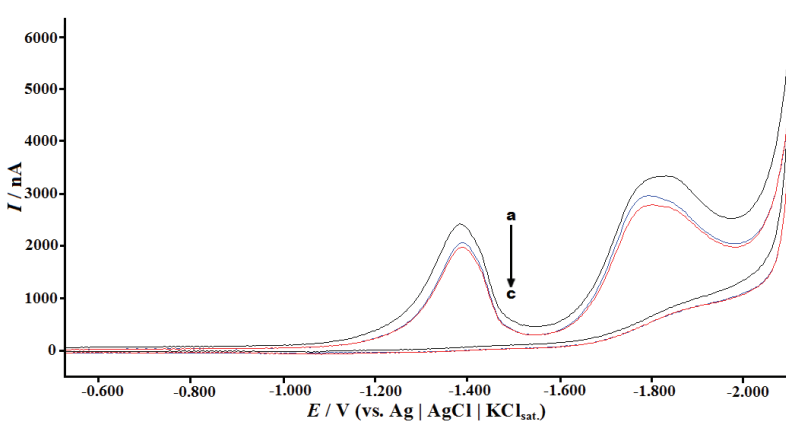

Figure 5. $\mathrm{CVs}$ of $9.90 \times 10^{-6} \mathrm{~mol} \mathrm{dm}^{-3} \mathrm{CP}$ solution, exposing to darkness at room temperature in B-R buffer $(\mathrm{pH}=9)$. a) $10, \mathrm{~b})$ 25, c) $35 \mathrm{~min}$.

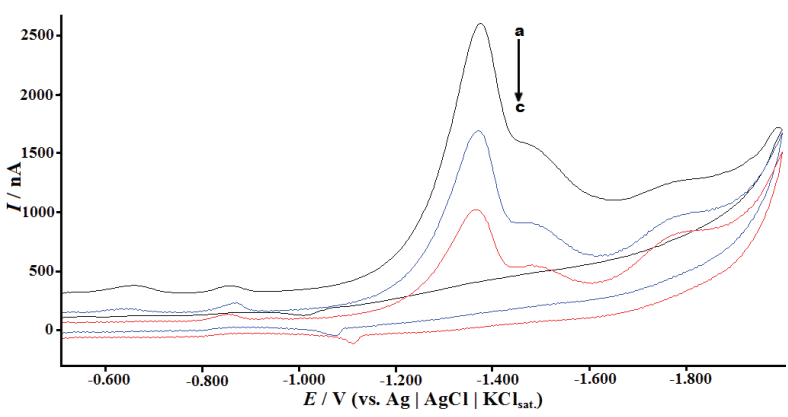

Figure 6. CVs of $\mathrm{CP}$ solution, exposing to darkness at room temperature in $\mathrm{B}-\mathrm{R}$ buffer $(\mathrm{pH}=11)$. a) $10, \mathrm{~b}) 20$, c) $30 \mathrm{~min}$.

group "untouched", while the $\mathrm{C}=\mathrm{C}$ bond is shifted in the alkaline media. Therefore, the reduction peak of $\mathrm{C}=\mathrm{C}$ bond should be much more affected from that of methoxyimino group. As can be seen in Figure 5, its peak potential versus waiting time is shifted to more positive potentials while the peak potential of first peak shows no shift at darkness. The kinetic data on the hydrolytic degradation of CP in darkness and basic medium are given in Table 1. 
Table 1. The pseudo first-order kinetic constants and half-life time for hydrolytic degradation of CP solutions under UVirradiation or in darkness at different $\mathrm{pHs}$

\begin{tabular}{rrrrrrc}
\hline \multirow{2}{*}{$\mathrm{pH}$} & \multicolumn{3}{c}{ UV-irradiation } & \multicolumn{3}{c}{ darkness } \\
\cline { 2 - 7 } & $k / \min ^{-1}$ & $t_{1 / 2} / \min$ & $r^{2}$ & $k / \min ^{-1}$ & $t_{1 / 2} / \min$ & $r^{2}$ \\
\hline 2.5 & 0.007 & 99.00 & 0.987 & - & - & - \\
5.0 & 0.003 & 231.00 & 0.988 & - & - & - \\
7.4 & 0.013 & 53.30 & 0.998 & 0.006 & 115.50 & 0.978 \\
9.0 & 0.017 & 40.76 & 0.996 & 0.017 & 40.76 & 0.990 \\
11.0 & 0.042 & 16.50 & 0.999 & &
\end{tabular}

The first order kinetic constant and half-life time The kinetic data for hydrolytic degradation of $\mathrm{CP}$ have been observed to obey a pseudo first-order rate equation as follows:

$$
\ln I_{\mathrm{pt}}=\ln I_{\mathrm{p} 0}-k \times t
$$

where, $I_{\mathrm{p} 0}$ and $I_{\mathrm{pt}}$ are currents of $\mathrm{CP}$ at time 0 and $t$ $(\mathrm{min})$, respectively. Also, $k\left(\mathrm{~min}^{-1}\right)$ is the first-order rate constant. $k$ can be obtained through a linear least-square fit of the $\ln I_{\mathrm{p}}$ data versus time. In above equation, it was thought that peak current was related to the bulk concentration of CP. The half-life $\left(t_{1 / 2}\right)$ is the time required to decrease the main peak current of $\mathrm{CP}$ to half of its initial value. It was calculated according to the following equation:

$$
t_{1 / 2}=0.693 / k
$$

In the presence of UV irradiation and in darkness, the values of the first order kinetic constants, determined from the plot of $\ln I_{\mathrm{pt}}$ versus $t$, are given in Table 1 . The values of half-life are also presented in Table 1.

As can be seen in Table 1, the $\mathrm{pH}$ and light had a significant effect on hydrolysis of $\mathrm{CP}$. The hydrolysis rate constant increased as $\mathrm{pH}$ increased from 5.0 to 11 , indicating that $\mathrm{pH}$ played an important role in hydrolysis of CP under UV light irradiation.

In darkness, it is very interesting that the hydrolysis of $\mathrm{CP}$ is only observed at basic $\mathrm{pH}$ values (9.0 and 11.0). In this case, the acidic and physiological conditions favoured the stability of $\mathrm{CP}$, and alkaline conditions increased the hydrolytic degradation rate of $\mathrm{CP}$; half-life time of $\mathrm{CP}$ decreased from 115.50 min. to 40.76 min. when $\mathrm{pH}$ increased from 9.0 to 11.0 (Table 1).

Photocatalytic effect was estimated by comparing the hydrolytic degradation of CP in UV light exposure and in darkness. Although the hydrolysis of $\mathrm{CP}$ was not seen in darkness at $\mathrm{pH}$ range 2.5-7.4, UV light exposure caused the considerable hydrolytic degradation of $\mathrm{CP}$ in this $\mathrm{pH}$ range. Also, UV light exposure increased hydro- lytic degradation of $\mathrm{CP}$, exhibiting the higher degradation rates than those under darkness at $\mathrm{pHs} 9$ and 11 (Table 1).

As can be seen in the presence of UV irradiation, the lowest $k$ was observed at $\mathrm{pH}$ 5.0. At $\mathrm{pH}$ range $5-11, k$ increased by increasing $\mathrm{pH}$ value. At $\mathrm{pH} 11, k$ is 14 times higher than that of $\mathrm{pH}$ 5. The catalysis of $\mathrm{OH}^{-}$ions in the hydrolysis of CP under UV-light irradiation was verified by the increase in hydrolysis rate constant as buffer $\mathrm{pH}$ increased from 7.4 to 11.0. Since $\mathrm{OH}^{-}$ions have much higher nucleophilicity than water molecules, ${ }^{37}$ its effect in the hydrolysis reaction of $\mathrm{CP}$ becomes more significant as the buffer solution $\mathrm{pH}$ increases. However, the degradation rate at $\mathrm{pH} 2.5$ may be increased from the acid catalysis under UV irradiation.

Cephalosporins were previously reported to produce sulfide ions upon alkaline degradation and it was found to be one of their major degradation products. $^{24,38}$ Also, Gouda et al. ${ }^{39}$ reported that Cefdinir, third-generation cephalosporin produced sulfide ions in the basic experimental conditions (in $0.5 \mathrm{~mol} \mathrm{dm}^{-3}$ $\mathrm{NaOH}, 100{ }^{\circ} \mathrm{C}$ and $30 \mathrm{~min}$.). On the other hand, the anodic depolarization of the mercury electrode by sulfide is well known. ${ }^{40}$ In the present study, the peak at $-0.746 \mathrm{~V}$ (Figure 2B, Inset) may be probably assigned to the mercury electrode reaction of sulphide species, formed from the hydrolytic degradation of $\mathrm{CP}$ in basic medium under UV irradiation. It is well known that the thiol products may be form by alkaline hydrolysis of the thioethers. ${ }^{41}$ Probably, UV-light accelerates the hydrolytic degradation of CP and also the formation of the sulphide species by means of basic medium.

Under UV-irradiation or in darkness, the positive shifting of the main peak potential and the decrease in the peak current of $\mathrm{CP}$ can be explained by the conversion of CP to cefpodoxime by means of hydrolysis. Cefpodoxime is electroactive and can be also reduced by $>\mathrm{C}=\mathrm{N}-\mathrm{OCH}_{3}$ group and also unsaturated $\mathrm{C}=\mathrm{C}$ bond as like in the $\mathrm{CP}$ molecule.

Although the borosilicate glass used in the experiments may partially absorb ultraviolet (UV) radiation, ${ }^{42}$ 
it is presumed that UV radiation has little direct influence on the hydrolysis based on photolysis reactions. ${ }^{43}$ The similar results have been also obtained in this study.

\section{CONCLUSION}

The hydrolytic degradation of $\mathrm{CP}$ in the presence of $\mathrm{UV}$-irradiation and in darkness was followed at $\mathrm{pH}$ range $2.5-11.0$ by cyclic and square -wave voltammetry techniques. While the hydrolysis of $\mathrm{CP}$ in darkness is only observed at basic $\mathrm{pH}$ values (9.0 and 11.0), the $\mathrm{CP}$ solutions are stable in the $\mathrm{pH}$ range 2.5-7.4. When compared to the results observed in darkness, it can be said that the rate of hydrolytic degradation of $\mathrm{CP}$ is increased by UV irradiation of its solutions. The results demonstrate that $\mathrm{CP}$ is a photo-labile drug. Owing to the decreases in the main peak current of $\mathrm{CP}$ and positive shifts in its potential, it can be postulated that $\mathrm{CP}$ undergoes hydrolysis to form cefpodoxime. Under UV-irradiation, $\mathrm{CP}$ has the maximum resistance $\left(t_{1 / 2}=231 \mathrm{~min}\right)$ for hydrolysis at $\mathrm{pH} 5$. Also, the rate of hydrolytic degradation of $\mathrm{CP}$ is increased by increasing $\mathrm{pH}$ in the $\mathrm{pH}$ range of 5.0-11.0. In addition, the hydrolysis kinetics of $\mathrm{CP}$ fitted well with a pseudo first-order reaction at the studied $\mathrm{pH}$ range (2.5-11.0). In basic medium ( $\mathrm{pH} 7.4-11.0)$, the hydrolysis of CP leads to a new electroactive product. These results will aid in the understanding of the anaerobic degradation of $\mathrm{CP}$ in the case of the aqueous environment conditions in the presence of UVirradiation and in darkness. We have established the best $\mathrm{pH}$ storage conditions for $\mathrm{CP}$, which are the following: a medium with a $\mathrm{pH}$ of 5 under UV light irradiation or a medium with a $\mathrm{pH}$ of 2.5 to 7.4 under darkness.

Acknowledgements. This work was supported by Ondokuz Mayıs University Research Fund for financial support through project number PYO.FEN.1901.11.004. The authors are thankful to Fargem A.Ş. (Düzce/Turkey) for providing CP sample used in this study.

\section{REFERENCES}

1. J. T. Carstensen and C. T. Rhodes, in: Drug Stability: Principles and Practices, $3^{\text {rd }}$ edition (revised and expanded), Marcel Dekker, New York, 2000.

2. B. D. Glass, Cs. Novák, and M. E. Brown, J. Therm. Anal. Calorim. 77 (2004) 1013-1036.

3. N. Fukutsu, T. Kawasaki, K. Saito, and H. Nakazawa, J. Chromatogr., A 1129 (2006) 153-159.

4. http://www.elmhurst.edu/ chm/vchembook/652penicillin.html (February 05, 2012).

5. S. Crauste-Manciet, M-O. Decroix, R. Farinotti, and J-C. Chaumeil, Int. J. Pharm. 157 (1997) 153-161.

6. M-J. Wang, W-B. Zou, J. Xue, and C-Q. Hu, Chromatographia 65 (2007) 69-75.
7. N. A. Nguyen, Pharm. Res. 8 (1991) 893-898

8. A. A. P. Khan, A. Mohd, S. Bano, and K. S. Siddiqi, J. Korean Chem. Soc. 53 (2009) 709-716.

9. T. Yamana and A. Tsuji, J. Pharm. Sci. 65 (1976) 1563-1574.

10. M. T. Borin, Drugs 42 (1991) 13-21.

11. J. C. Rodríguez, R. Hernández, M. González, Z. Rodríguez, B. Tolón, H. Vélez, B. Valdés, M. A. López, and A. Fini, Il Farmaco 58 (2003) 363-369.

12. N. Fukutsu, T. Kawasaki, K. Saito, and H. Nakazawa, Chem. Pharm. Bull. 54 (2006) 1340-1343.

13. K. Stoeckel, W. Hofheinz, J. P. Laneury, P. Duchene, S. Shedlofsky, and R. A. Blouin, Antimicrob. Agents Chemother. 42 (1998) 2602-2606.

14. V. K. Kakumanu, V. Arora, and A. K. Bansal, Int. J. Pharm. 317 (2006) 155-160.

15. T. M. Reddy, M. Sreedhar, and S. J. Reddy, J. Pharm. Biomed. Anal. 31 (2003) 811-818.

16. R. Jain, R. Mishra, and A. Dwivedi, J. Sci. Ind. Res. India 68 (2009) 945-950.

17. D.A. Hall, D. M. Berry, and C. J. Schneider, J. Electroanal. Chem. 80 (1977) 155-170.

18. P. Zuman, V. Kapetanovic, and M. Aleksic, Anal. Lett. 33 (2000) 2821-2857.

19. M. Aleksić, M. Ilić, and V. Kapetanović, J. Pharm. Biomed. Anal. 36 (2004) 899-903.

20. M. Miyauchi, K. Sasahara, K. Fujimoto, I. Kawamoto, J. Ide, and H. Nakao, Chem. Pharm. Bull. 37 (1989) 2369-2374.

21. M. Zając, A. Jelińska, L. Dobrowolski, and I. Oszczapowicz, J. Pharm. Biomed. Anal. 32 (2003) 1181-1187.

22. A. Jelińska, M. Zając, J. Gostomska, and M. Szczepaniak, Il Farmaco 58 (2003) 309-313.

23. B. A. Olsen, F. M. Perry, S. V. Snorek, and P. L. Lewellen, Pharm. Dev. Technol. 2 (1997) 303-312.

24. A. A. Alwarthan, F. H. Metwally, and S. A. Al-Tamimi, Anal. Lett. 26 (1993) 2619-2635.

25. D. Omanović and M. Branica, Croat. Chem. Acta 71 (1998) 421-433.

26. O. C. Zafiriou and M. McFarland, Anal. Chem. 52 (1980) 1662-1667.

27. http://www.svetila.com/en/ultra-vitalux-300w-1170.html (February 05,2012 ).

28. W. M. Todd, Int. J. Antimicrob. Agents 4 (1994) 37-62.

29. E. Palecek, J. Osteryoung, and R. A. Osteryoung, Anal. Chem. 54 (1982) 1389-1394.

30. L. Hernández, P. Hernández, M. Rica, and F. Galán, Anal. Chim. Acta 315 (1995) 33-39.

31. L. N. C. Rodrigues, M. V. B. Zanoni, and A. G. Fogg, Anal. Lett. 32 (1999) 97-109.

32. L. N. C. Rodrigues, M. V. B. Zanoni, and A. G. Fogg, J. Pharm Biomed. Anal. 21 (1999) 497-505.

33. X. Hu, J. Yang, C. Yang, and J. Zhang, Chem. Eng. J. 161 (2010) 68-72.

34. A. Álvarez-Lueje, L. Naranjo, L. J. Núñez-Vergara, and J. A. Squella, J. Pharm. Biomed. Anal. 16 (1998) 853-862.

35. C. M. P. Vaz, P. R. V. Silva Jr., I. Prado, G. M. Castanho, F. R. Simões, and S. A. S. Machado, Quim. Nova 31 (2008) 1310-1314.

36. A. Álvarez-Lueje, S. Pujol, L. J. Núñez-Vergara, and J. A. Squella, J. AOAC Int. 85 (2002) 1247-1252.

37. R. P. Schwarzenbach, P. M. Gschwend, and D. M. Imboden, in: Environmental Organic Chemistry, R. P. Schwarzenbach et al., Eds., JohnWiley\&Sons, New York, 1993, pp. 359-368.

38. A. H. Rageh, S. R. El-Shaboury, G. A. Saleh, and F. A. Mohamed, Natural Science 2 (2010) 828-840.

39. A. A. Gouda, H. Hashem, and W. Hassan, Drug Test. Anal. 4 (2011) 991-1000. 
40. G. W. Luther, A. E. Giblin, and R. Varsolona, Limnol. Oceanogr. 30 (1985) 727-736.

41. R. Tardif, D. Talbot, and M. Gérin, J. Anal. Toxicol. 12 (1988) 42-44.
42. L. R. Koller, in Ultraviolet Radiation, $2^{\text {nd }}$ ed., John Wiley \&Sons, New York, 1965, pp. 162-163.

43. M. Guo, S. K. Papiernik, W. Zheng, and S. R. Yates, J. Environ Qual. 33 (2004) 612-618. 